\title{
La biblioteca pública del s. XXI: atendiendo clientes, movilizando personas (Roser Lozano-Díaz)
}

\author{
Por Eulàlia Espinàs
}

Espinàs, Eulàlia. "La biblioteca pública del S. XXI: atendiendo clientes, movilizando personas (Roser Lozano-Díaz)". En: El profesional de la información, 2007, julio-agosto, v. 16, n. 4, pp. 387-388.

DOI: 10.3145/epi.2007.jul.16

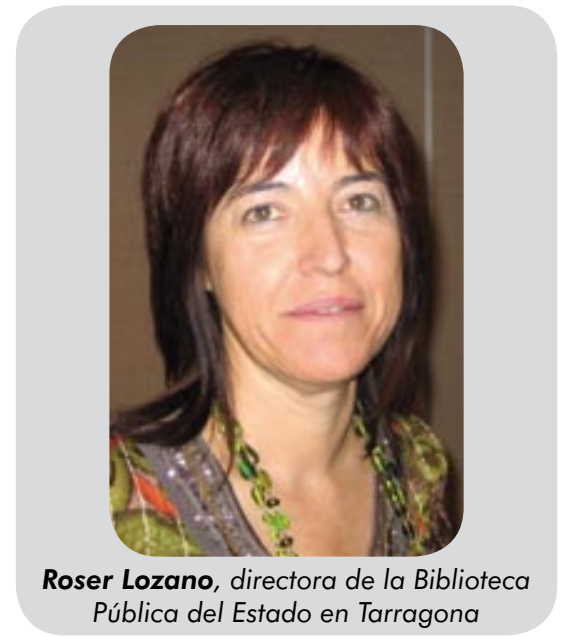

EL PASADO 17 DE MAYO DE 2007 se presentó en Tarragona, la ciudad profesional de Roser Lozano, el libro que dicha autora acaba de publicar de la mano de la editorial Trea.

Para introducirnos de lleno en el contenido del libro es conveniente aproximarnos a la trayectoria y capacidad profesional de la autora, ya que el libro emana directamente de su experiencia.

Desde su tenacidad en ofrecer a los ciudadanos de Tarragona una biblioteca viva, que procura día a día proporcionar el máximo de servicios, acercarles el pulso de la actualidad y dar respuesta a lo que demandan, hasta su voluntad en dar a conocer a los profesionales de España, y allende los mares, que este modelo de biblioteca es posible, por qué es importante potenciarla y cómo puede hacerse realidad. Todo ello con un entusiasmo contagioso.

\section{Bibliotecas públicas en evolución}

El libro expone una concepción de las bibliotecas públicas que define la esencia de las mismas, por lo que fueron creadas y por lo que se han mantenido vigentes a lo largo de las épocas y de lo cambios tecnológicos y sociales.

La biblioteca pública actual nace con el desarrollo industrial, junto a los núcleos poblacionales que éste genera y siguiendo las ideas sociales igualitarias, en las que educación y cultura se convierten en un elemento básico para educación del ser humano y para la construcción de una sociedad más justa. En aquel momento las bibliotecas tuvieron un papel importante, como centro de acogida, cultural y de formación, participando muy activamente en los procesos de alfabetización y de difusión de la cultura.

A lo largo de la historia, su rol se ha concretado en tres ejes básicos de actividad:

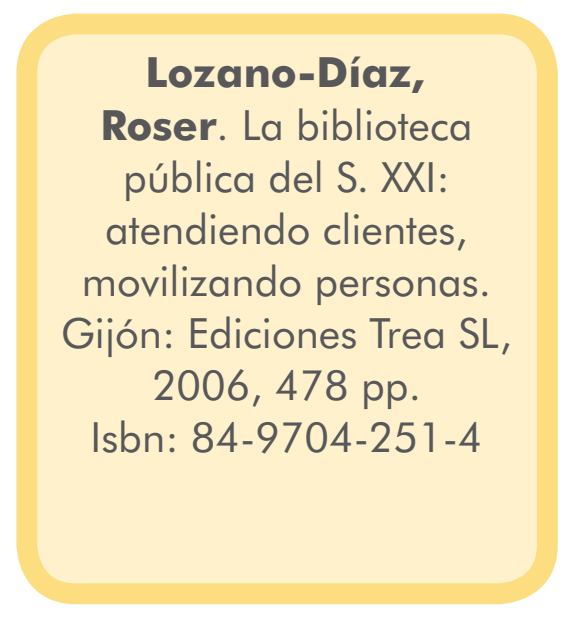

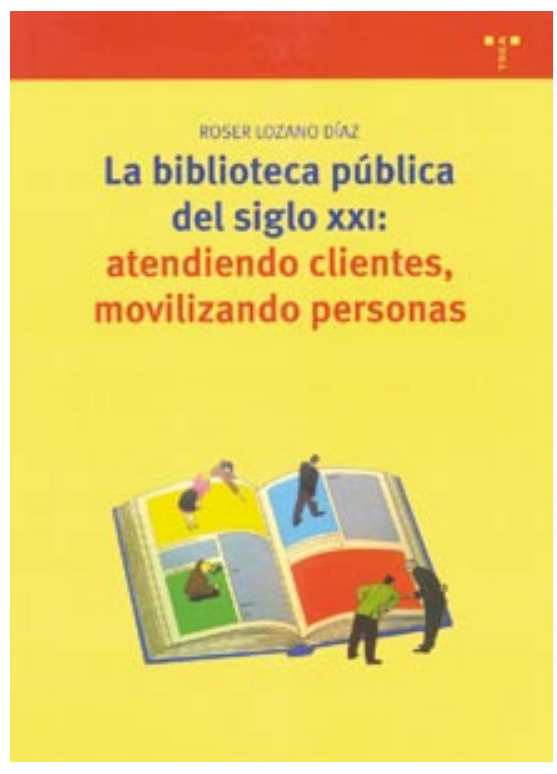

1. Garantizar el acceso universal a la información por parte de todos los ciudadanos -derecho universal reconocido en los derechos del hombre y en las constituciones de muchos países-, provengan de donde provengan e indistintamente del soporte documental en el que la información se encuentre.

2. Acompañar a los ciudadanos en su evolución intelectual, ya sea en su etapa formativa inicial, en la profesional o en su vida cotidiana. En este marco, su actual implicación con la alfabetización informacional de la gente es una fase más de las diferentes alfabetizaciones en las que la biblioteca ha contribuido a lo largo de la historia.

3. Ofrecer un espacio de encuentro, de intercambio entre ciudadanos, donde poder mostrar y participar del ocio cultural por parte de éstos. 
Vemos, pues, que las bibliotecas públicas mantienen la "esencia" por la que nacieron, si bien en determinadas latitudes - la nuestra es una muestra-, este fenómeno sufrió a lo largo de muchos años del s. XX una importante involución y se debe recuperar. Por ello es tan importante que profesionales que han trabajado y trabajan en hacer de esta esencia una realidad, dediquen una parte de su tiempo a escribir no sólo lo que piensan, sino a diseñar qué es lo que se puede hacer y cómo en nuestro entorno más inmediato.

\section{Ideas clave del libro}

Se ponen encima de la mesa los factores que actualmente determinan los servicios bibliotecarios, en concordancia con el entorno más global del sector servicios y de la sociedad en general.

En una sociedad del bienestar, lejos ya del "vuelva usted mañana", los ciudadanos piden nuevos servicios públicos: formas emergentes de comunicarse en un mundo audiovisualmente publicista; demandas sociales de información, tratadas con nuevas herramientas tecnológicas y que ofrecen nuevas posibilidades de oferta de servicios. Ello conlleva un cambio profundo entre los profesionales, tanto en su formación, como en su actitud, conocimientos, relación con otras instituciones, etc.

El libro introduce conceptos desarrollados con éxito en otros entornos, pero que hasta hace poco no eran muy usuales en el mundo cultural y bibliotecario, y que aún hoy son un reto en los servicios públicos, proponiéndonos aplicarlos en la biblioteca.

Se desgrana, de forma muy bien estructurada, no sólo su marco teórico sino que llega hasta su núcleo, exponiéndolos hábilmente, para que los profesionales no lo vivan como un valladar sino que se sientan motivados a hacerlos realidad.

En esa tesitura, el libro se convierte en un auténtico manual para profesionales en el que se recorren las siguientes aspectos clave:

- gestión del cambio en las bibliotecas públicas, qué lo acelera y qué lo frena, como se puede impulsar y cómo hacerlo de forma planificada aprovechando las oportunidades que brinda a la propia biblioteca.

- planificación estratégica en los servicios públicos, importancia de la rentabilidad social, competencia, nichos de acción..., y la necesidad de trabajar por objetivos, dando un cambio de enfoque a los procesos internos, que pasan de estar orientados del documento al usuario.

- gestión del conocimiento, recursos tangibles e intangibles, cómo desarrollar nuevas fuentes de información, y cómo emprender la necesaria transformación de la biblioteca de una organización que ofrece a una organización que aprende.

- la conversión de los ciudadanos en clientes, cómo atraerlos y retenerlos, cómo conocer a la comunidad a la que se debe dar servicio, pensar las estrategias para hacer más transparente la comunicación con ella y aplicando los principios de calidad, buscando la satisfacción de sus necesidades y sus expectativas, lo que se conoce por una biblioteca orientada al ciudadano.

\section{"Apuesta por la participación activa tanto de los ciudadanos en la vida de la biblioteca, como de la biblioteca en la sociedad civil"}

\section{Cambio de paradigma}

Como afirma Manuel Castells, estamos viviendo un cambio de paradigma provocado por la introducción de las TIC en todos los aspectos de la sociedad "las nuevas tecnologías de la información no son sólo herramientas que aplicar, sino procesos que desarrollar. Los usuarios y los creadores pueden ser los mis$\operatorname{mos}^{1 "}$

Y esto es lo que también pone de relieve Roser Lozano: el paso necesario de convertir los usuarios pasivos en usuarios partícipes, en ciudadanos que contribuyen a la construcción de los propios servicios y de la propia biblioteca.

Un capítulo entero dedica la autora a la interacción entre la biblioteca y la comunidad, a la cooperación, a la búsqueda de sinergias en las dos direcciones. Apuesta por la participación activa de los ciudadanos en la vida de la biblioteca, y por un acercamiento y participación de la biblioteca en la sociedad civil.

Éste es el reto real que tienen los servicios públicos, y la autora ofrece algunas reflexiones y expone los factores clave para que ello pueda hacerse realidad en las bibliotecas públicas actuales.

Todo el libro tiene un gran interés y puede contribuir a introducir cambios importantes en el sector de los servicios públicos y en concreto el de las bibliotecas públicas. Pero este último capítulo contiene la clave, es el que justifica que las bibliotecas en la era de internet, tengan aún sentido de existir o, mejor dicho, tengan más sentido que nunca. Como una invitación a volver de nuevo, de algún modo, a "su esencia".

\section{Nota}

1. Manuel Castells. "La era de la información: economía, sociedad y cultura. Volumen I: La sociedad red". Barcelona: Editorial UOC, 2003, pág. 64.

Eulàlia Espinàs, presidenta del Co$b d c$

Generalitat de Catalunya, Departament de Cultura.

Portal de Sta. Madrona, 6-8, 08001 Barcelona

Tel.: +34-933162 780, ext. 8719

eespinasgencat.net 


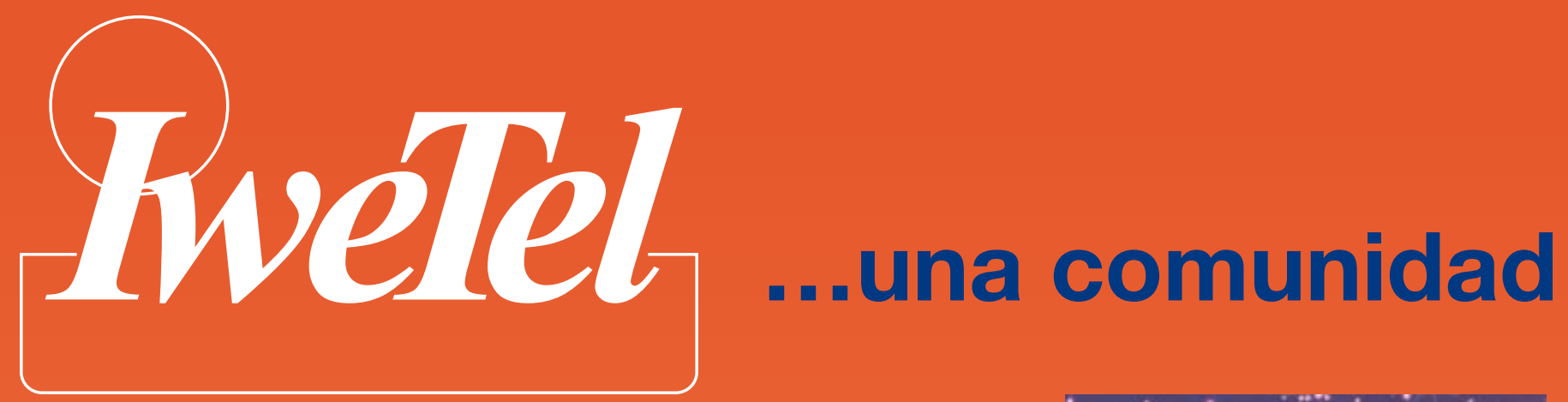

\section{de 5.000 profesionales}

\section{de la información}

\section{ivente al nuevo}
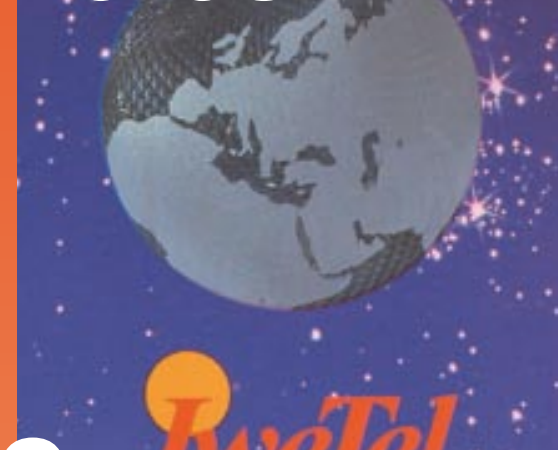

una lista que sólo distribuye contenidos de calidad.

- participa en discusiones de gran interés para tu trabajo,

- conoce cuáles son temas que afectan a la profesión,

- está al día de todo cuanto sucede...

Inscribirse es rápido

y gratuito
Sólo tienes que mandar este mensaje: subscribe iwetel Nombre Apellido(s) a la dirección: listserv@rediris.es o bien conectarte con esta web: 